'|||||||||||||||||||||||||||||||||||||||||||||||||||||||||||.

\section{The Middle Way}

Dear Reader,

Germany intends to become climateneutral, not by 2050 , but by 2045 . At least, that is what the politicians are planning. Some people are of the opinion that these plans are naïve, because they do not believe that the goal is achievable. Others think that 2045 is much too late and will not allow us to meet the target of the Intergovernmental Panel on Climate Change for a maximum increase in global temperatures of $1.5^{\circ} \mathrm{C}$. If we continue as before, the world's remaining carbon budget, in other words, the amount of fossil greenhouse gases that can still be emitted, will be used up within the next seven years. By cutting emissions we can reduce the pressure on this budget, but will that really happen?

Scientists from a number of different disciplines, including Prof. Thomas Willner, a process engineer from Hamburg University of Applied Sciences (HAW), and Prof. Thomas Koch from the Karlsruhe Institute of Technology (KIT), have made it clear in open letters that the current political course will not lead to any real reductions in $\mathrm{CO}_{2}$, because the laws of physics are being distorted by computer models. The problem is that, because of the obvious weaknesses of this type of simulation, the discussions that we actually need to have about protecting the climate are descending into a completely pointless form of trench warfare. Instead of developing serious solutions, we are repeating the same tired arguments again and again.

We need to make immediate and lasting reductions in emissions in every area of our lives if we are to achieve success. The current accounting method, which uses emission factors and fails to include carbon-neutral fuels, does not meet these criteria. In the long term, there will definitely be further changes, but the solutions must prove their worth from every perspective in order to have a lasting impact. Creating a sustainable infrastructure, for example in the MENA states, is not only environmentally friendly, but also brings social benefits by enabling and empowering regional developments. There is unlikely to be any objection to fuels made from organic or plastic waste, as these solutions resolve several problems at once. Excluding modern combustion engines and synthetic fuels from the subsidy schemes is definitely the wrong approach. On the one hand, they can and will be climateneutral and, on the other, for many applications there are simply no alternatives, not only in transport, but across all sectors of the economy. Moreover, demonizing electric vehicles serves no useful purpose. We need to find the middle way between the two extremes.

I hope you enjoy this issue of ATZheavyduty.

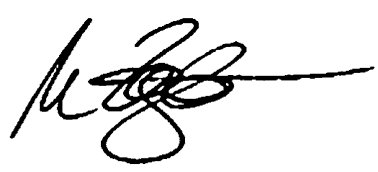

Marc Ziegler

Deputy Editor in Chief MTZ

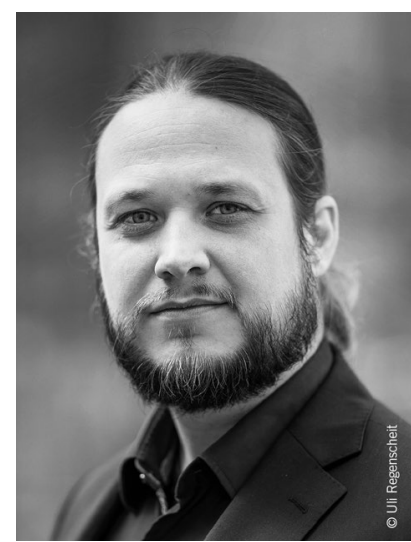

\section{GET A GRIP ON SUCCESS} क्र

To achieve new heights, you will need adhesion: the trade journal for industrial adhesives and sealing technology providing valuable insider knowledge, practical information and the latest trends and technologies.

$\checkmark 4$ issues every year

$\checkmark$ Includes digital edition - NEW!

$\checkmark$ Free "Adhesives Technology Compendium" for subscribers the reference book for adhesives practitioners

$\checkmark$ Free access to online archive with expert articles since 2009

$\checkmark$ No risk, cancel anytime

Register now for your free trial subscription: www.my-specializedknowledge.com/adhesion
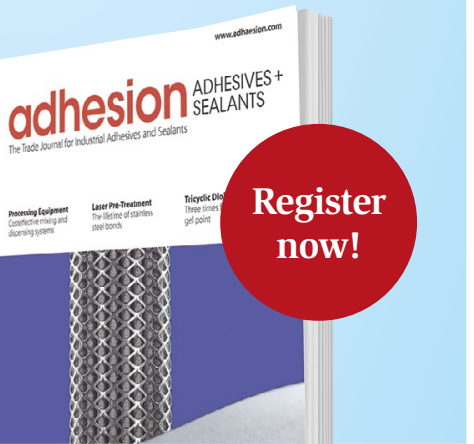

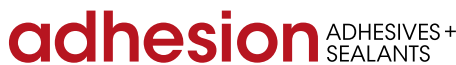

